\title{
FRANCESCO PATRIZI E A CRÍTICA À CONCEPÇÃO HISTORIOGRÁFICA DO "BURLESCO” LUCIANO
}

\author{
Helvio Moraes $\star$ \\ Universidade do Estado do Mato Grosso
}

\begin{abstract}
The series of norms and considerations about the historiographic work established by Lucian in his How to Write History exercised a great influence on the genre of the ars historica in Renaissance. If Cicero's De oratore is the main literary source for the recovery of the exemplum, Lucian's work is often called into question in regard to issues related to the writing of the historical account, such as diction and style, brevity, syntax, as well as the qualities of a good historian. The crisis of this model of humanist historiography will be criticized by Francesco Patrizi da Cherso, in his "Della historia diece dialoghi", published in 1560 in Venice. In the opening dialogues, Patrizi condemns the early humanists' diligent affiliation to the auctoritates, in an endeavor to bring down the basis from which the whole preceding historiography was built. Thus, this article aims at: 1) evincing the presence of Lucian's work in humanist historiography; and 2) examining the sense of Patrizi's criticism of the principles given by the "beffardo" Luciano.
\end{abstract}

KEYWORDS: Ars historica; humanist historiography; rhetoric; Lucian.

\section{I}

amplo corpus de escritos que se vinculam ou se aproximam do gênero da ars historica teve o auge de sua produção após a última sessão do Concílio de Trento, mas sua origem remonta às reflexões dos primeiros humanistas italianos. O século XVII ainda assiste ao surgimento de alguns tratados de ars historica, mas seus postulados

\footnotetext{
*helviomoraes.unemat@gmail.com
} 
repetem à exaustão os lugares-comuns da tratadística anterior, o que nos faz observar que a tentativa de determinar regras para a escrita historiográfica, assim como a reflexão sobre a utilidade e o significado da história (próprias do gênero), vão cedendo lugar ao método, e o conhecimento histórico começa a ser visto como um legítimo objeto de investigação filosófica, independentemente de sua utilidade política ou moral.

Como qualquer outro campo da produção intelectual do período, a ars historica fundamenta-se na leitura, às vezes pontual, das ideias legadas pelas auctoritates, expressas principalmente em passagens da Poética de Aristóteles, em alguns escritos de Cícero (principalmente o De Oratore) e em Como se deve escrever a História, de Luciano de Samósata, para muitos o único tratado de ars historica escrito na Antiguidade. Esperamos que a escolha pelo termo "leitura" forneça a conotação que pretendemos: a de que o resgate da literatura clássica não implica uma imitação incondicional de seus modelos, mas é, antes, solicitado por circunstâncias históricas muito específicas, no momento em que, dada a realidade política italiana ou a manifestação de várias realidades ético-políticas muito particulares, ${ }^{1}$ o humanismo assume uma postura diferente em relação ao passado, quando, ao mesmo tempo em que com ele se compara, o relativiza, tomando-o de forma perspectiva, e este distanciamento torna possível o surgimento de uma consciência histórica, para dizermos como Eugenio Garin. ${ }^{2}$

Portanto, as primeiras elaborações humanistas sobre a história, amplamente inspiradas nos cânones da Antiguidade, por muito tempo passaram despercebidas, justamente por não se encontrarem formuladas em escritos exclusivamente dedicados ao assunto, mas, sim, dispersas em prefácios e dedicatórias de obras historiográficas ou em epístolas, discursos, invectivas, sendo que somente no fim do Quattrocento será publicada a primeira ars historica tout court, o diálogo Actius de Giovanni Pontano, síntese das discussões humanistas precedentes sobre o tema, em que se estabelece um forte vínculo entre história, poesia e retórica, seguindo, principalmente, os preceitos de Cícero, Quintiliano e Luciano. De forma geral, embora estes primeiros humanistas salientem a importância da veracidade do relato histórico, para muitos o emprego do ornamentum e da amplificatio é visto como um expediente legítimo, principalmente quando se recorre ao uso de discursos diretos (que será um tema polêmico em tratados dos séculos seguintes), na maior parte

\footnotetext{
${ }^{1}$ Cf. Vegas, op. cit., p. 26.

${ }^{2}$ Cf. Garin, op. cit., 1993, p. 21-22.
} 
dos casos, para mostrar e explicar as diferentes posições de adversários quando em debate ou na iminência de batalhas, ou até mesmo para revelar juízos do próprio historiador.

Da mesma forma, grande parte da historiografia humanista, que remonta aos escritos de Leonardo Bruni, é fortemente marcada pelos postulados clássicos dos latinos, daí sua forte relação (Francesco Patrizi diria subordinação) com a retórica. Grande importância é atribuída aos exempla, e a história, desta maneira, passa a ser vista como um vasto repertório de grandes feitos realizados por ilustres personagens, que, manipulados de forma adequada, servem a várias finalidades, que vão desde a glorificação de príncipes e cidades até a edificação moral do homem. A atenção a um estilo elegante, um modo de "vestir a história de modo a torná-la uma forma de literatura", ${ }^{3}$ em contraste com o estilo das crônicas medievais, assim como um cuidado maior com a dispositio do discurso histórico (ausente nos anais), são aspectos que determinam o caráter de tais escritos. De fato, parece haver uma primazia da forma sobre o conteúdo, uma precedência do "apelo sensual (...) sobre o método racional", ${ }^{4}$ característico do discurso de persuasão, que tende a fornecer ao relato uma combinação de voluptas e utilitas. ${ }^{5}$

Assim, o De oratore de Cícero faz-se perceber mais facilmente na produção historiográfica, como a fonte principal para a retomada do exemplum, não só como modelo a ser imitado ou rejeitado na ação política, mas também como um paradigma moral. Além disso, o orador romano é sempre uma referência quando se trata de justificar a obra historiográfica como opus oratorium maxime, e jamais deixará de ser citada sua célebre definição da história como "testemunha dos séculos, luz da verdade, vida da memória, mestra de vida, mensageira do passado", o que, segundo Hartog, "supõe a intervenção do orador", no sentido de que, para ser tudo isso de forma plena e duradoura, "tem a necessidade de que o orador lhe empreste sua voz".

Por seu caráter mais prescritivo (se atentarmos à segunda parte), o tratado de Luciano ocupa várias páginas das reflexões dos humanistas sobre a história. Dele se origina a maior parte das questões relacionadas à escrita do relato historiográfico, referentes às qualidades do historiador

\footnotetext{
${ }^{3}$ Cf. Ullman, op. cit., p. 326. A tradução dos textos estrangeiros, em todo o artigo, foi feita pelo autor.

${ }^{4}$ Cf. Reynolds, op. cit.,p. 115.

${ }^{5}$ Cf. Kelley, op. cit., p. 748.

${ }^{6}$ Cf. Hartog, op. cit., p. 181.
} 
e a especificidades como dicção e estilo, brevidade, disposição das palavras e - talvez a mais relevante e igualmente polêmica - a introdução de discursos diretos. O escrito de Luciano é também fonte de outra premissa que se tornará comum principalmente nas reflexões do segundo humanismo: a de que o fim do relato historiográfico é sua utilidade política, e não simplesmente o prazer. ${ }^{7}$ Isso se vincula à defesa da veracidade da narração histórica por parte do autor, o que, consequentemente, o leva a estabelecer limites entre história e poesia, linguagem histórica e linguagem poética, a liberdade sóbria do historiador face à pura liberdade do poeta, ${ }^{8}$ tornando clara a acusação que faz na primeira parte do tratado às desmedidas retóricas dos historiadores de seu tempo.

Embora não seja tão fácil estabelecer uma ligação direta entre ars historica e prática historiográfica, pode-se perceber que esta também evidencia a incidência do escrito de Luciano: as historie dos humanistas privilegiam as gesta de príncipes e de repúblicas, seus temas inscrevemse no âmbito da política e da guerra, os procedimentos narrativos obedecem às regras propostas pelo sírio, ainda que muitos autores pareçam não se lembrar de sua principal advertência: a de que se deve levar em conta que há uma separação entre o elogio e a história.

Sendo assim, enquanto o clima intelectual mantém-se receptivo ao livre intercâmbio de ideias como forma de participação na vida política e à busca de uma concordia entre eloquência e conhecimento filosófico (aquela sendo a forma de expressão deste), numa espécie de versão do ideal renascentista da vita pratica, as máximas e os preceitos dos antigos serão constantemente retomados e relidos. É, porém, no ambiente do entre e pós-reformas que se registra a crise do modelo historiográfico humanista ou, pelo menos, a presença de alguns indícios de um procedimento em crise, através das severas críticas feitas por Francesco Patrizi da Cherso em seus Dialoghi della Historia, publicados em 1560 em Veneza. Neles, Patrizi aponta os limites da concepção de história de seu tempo, desaprova sua zelosa filiação às auctoritates (incluindo, obviamente, Luciano) e abala, assim, o alicerce sobre o qual foi construída toda a historiografia precedente. Por fim, empreende uma busca, não de todo conclusiva, por uma nova teoria da história, mais abrangente e

\footnotetext{
${ }^{7}$ Cf. Brandão, op. cit., p. 23: Não se nega que a história deva provocar algum prazer, mas pretende-se que o prazeroso acompanhe o útil, “como a beleza ao atleta”, e não o inverso.

${ }^{8}$ Cf. Brandão, op. cit.
} 
autônoma, como primeiro passo de uma "sua tão elevada empresa de toda a eloquência": ${ }^{9}$ em Patrizi a ars historica postula seu próprio fim.

Nosso objetivo é, portanto, assinalar a importância do escrito de Luciano para a concepção historiográfica do Renascimento, fazendo pontuais considerações sobre os principais textos que o tomam como referência, desde o momento em que se estabelece uma espécie de filiação a suas determinações, como se dá nos escritos de Guarini da Verona, Giovanni Pontano e Francesco Robortello, até a assunção de uma postura contrária, como é o caso de Francesco Patrizi, o que nos fará investigar o sentido de sua crítica aos preceitos do "burlesco" Luciano.

\section{II}

Guarino da Verona é o primeiro humanista a difundir as ideias centrais do tratado de Luciano, numa epístola que escreve durante o carnaval de 1446 a Tobia del Borgo, recém-nomeado historiógrafo da corte de Rimini. ${ }^{10}$ Seu propósito é aconselhar o amigo em relação a seu novo encargo de celebrar os feitos de Sigismondo Malatesta. Assim diz -,"enquanto a cidade ressoa com os scherzi e as danças, num breve intervalo reuni para ti algumas normas [úteis] à tua tarefa e, esperando que te sejam oportunas, decidi com elas fazer uma espécie de tratado sumário para que o mantenhas sob os olhos". ${ }^{11}$

As normas coligidas por Guarino podem ser facilmente identificadas nos escritos de Cícero e de Luciano. De fato, somente o primeiro é citado, enquanto nenhuma menção é feita ao pensador sírio, ainda que a ele se remeta na maior parte das ideias expressas no tratatello, a ponto de o texto ser visto por Grafton ${ }^{12}$ como uma adaptação, e por Regoliosi, ${ }^{13}$ como uma versão em tradução quase literal de trechos do original grego. Regoliosi acredita ainda que na omissão do nome de

\footnotetext{
${ }^{9}$ Cf. Patrizi, op cit., p. A2. De fato, Patrizi leva a cabo tal "impresa", a seguir, com a publicação dos Dieci Dialoghi della Retorica, em 1562, e, por fim, dos diálogos Della Poetica, cujas primeiras partes (Deca istoriale e Deca disputata) são publicadas em 1586, ainda que ele leve mais dois anos para terminar o conjunto de diálogos, que permaneceram inéditos até 1969, quando então receberam uma edição organizada por Danilo Aguzzi Barbagli.

${ }^{10}$ Cf. Garin, op. cit., 1958, p. 383.

${ }^{11}$ Cf. Guarino da Verona, apud Garin, op.cit., 1958, p. 387.

${ }^{12}$ Cf. Grafton, op. cit., p. 35.

${ }^{13}$ Cf. Regoliosi, op. cit., p. 10.
} 
Luciano possa estar a prova de que realmente tenha sido através de Guarino a "primeira divulgação oficial" do tratado no âmbito das discussões humanistas, como uma "raridade/novidade cultural - por isso totalmente dissimulada". ${ }^{14}$

Enquanto Luciano estabelece como fim da obra historiográfica a sua utilidade política, Guarino não resiste à ideia de concebê-la como uma celebração retórica, no seu anseio por "formar escritores capazes de confiar [os feitos bélicos] aos monumentos das letras, e de ilustrálos com os seus escritos, evitando que a memória dos homens morra com os homens". ${ }^{15}$ A Tobia del Borgo, afirma: “[É] teu débito de gratidão empenhar-se em celebrar seus [de Sigismondo Malatesta] feitos, e difundir sua fama, dedicando à exaltação deste príncipe o quanto há em ti de engenho, de cultura, de arte". ${ }^{16}$

Não obstante, Guarino introduz o tema da utilitas, que será caro à tratadística posterior. Segue de perto as prescrições de Luciano que visam a este fim, como a relevância da veracidade do relato, a imparcialidade e a liberdade de espírito do historiador, o domínio de sua vontade face ao elogio dos amigos e vitupério dos rivais, entre outras. Contudo, por seu intermédio, a noção de utilitas se impregna dos valores sustentados pela tradição ciceroniana e torna-se híbrida, no sentido de que é possível vislumbrar um estímulo à ação política, ainda que sob a forte carga moral contida no exemplum:

O primeiro fim da história, e sua única razão de ser, é a utilidade que deriva do próprio fato de se dizer a verdade de modo a tornar o espírito, através do conhecimento dos eventos passados, mais sábio no operar, mais fervoroso no imitar exemplos de valor e de glória e outras coisas do gênero. ${ }^{17}$

Como se percebe, tal ideia ainda está distante da asserção de Luciano de que "a utilidade é o fim da história, de modo que, se alguma vez, de novo, acontecem coisas semelhantes, se poderá, diz ele [Tucídides], consultando-se o que foi escrito antes, agir bem com relação às circunstâncias que se encontram diante de nós" (Luciano, 42). Algumas décadas ainda haverão de passar, até que Maquiavel retome

\footnotetext{
${ }^{14}$ Cf. Regoliosi, op. cit., p. 10.

${ }^{15}$ Cf. Guarino da Verona, apud Garin, op.cit., 1958, p. 385.

${ }^{16}$ Cf. Guarino da Verona, apud Garin, op.cit., 1958, p. 385.

${ }^{17}$ Cf. Guarino da Verona, apud Garin, op.cit., 1958, p. 389.
} 
esta ideia como um dos fundamentos de seu pensamento político. Mas o ambiente cultural de que Guarino participa privilegia o vínculo entre as várias disciplinas que compõem juntas um vasto saber enciclopédico, herdeiro da tradição clássica e construído sobre as bases de uma sólida cultura retórica.

Portanto, são muito bem acolhidas as considerações de Luciano quanto às especificidades da história e da poesia e seus respectivos modos discursivos, visto que não saem da ampla esfera da disciplina retórica, pelo contrário, dentro dela encontram seus lugares específicos. A uma linguagem poética, que "não teme tornar alados os cavalos e transformar os mortais em divindades", é contraposta a visão da história como "matrona pudica, [que] nada ousa dizer que se possa criticar, desaprovar, acusar de mentira". ${ }^{18}$ À acusação da adulação, ainda que não seja "vetado ao historiador o elogio de pessoas, desde que comedido e oportuno", se opõe um estilo

rico de expressões usadas por escritores prestigiosos, aberto, viril, capaz de exprimir os fatos com eficácia, não [se utilizando de] termos forenses, artificiosos, obscuros, fora do comum, mas claros, dignos, graves, a todos compreensíveis, a que as pessoas cultas possam exaltar e admirar, um estilo, em suma, conveniente "ao historiador, não ao trágico, não às causas do fórum". ${ }^{19}$

A inclinação literária de Guarino, assim como o caráter compilatório de seu escrito, acaba por privar suas formulações do vigor argumentativo e da coerência que notamos em Luciano. Causa um certo incômodo contrastar a parte prescritiva de sua epístola, com todo o rigor normativo do modelo em que se inspira (ainda que combinado a loci comunes ciceronianos), com o longo exórdio, em que justamente se tece um aberto elogio a Sigismondo Malatesta, "êmulo e imitador dos antigos, $[\ldots]$ valorosíssimo soldado, valentíssimo condottiere, que, voltando-se à conquista da glória sobre os exemplos valorosos dos pais, cultiva e atrai, com ingentes prêmios, homens doutos e eruditos". ${ }^{20}$

Obviamente, isso não diminui em nada a importância deste documento que coloca em circulação novas ideias sobre a história, sem falar de suas qualidades literárias que, por si mesmas, o colocam entre

\footnotetext{
${ }^{18}$ Cf. Guarino da Verona, apud Garin, op.cit., 1958, p. 389.

${ }^{19}$ Cf. Guarino da Verona, apud Garin, op.cit., 1958, p. 393-395.

${ }^{20}$ Cf. Guarino da Verona, apud Garin, op.cit., 1958, p. 385.
} 
o que de melhor a primeira fase do humanismo italiano produziu. A partir de Guarino, os autores de ars historica, em algum ponto de suas reflexões, serão obrigados a tratar de temas como a utilidade da história, a função do historiador, a linguagem da obra historiográfica, a forma de inserção de discursos diretos, temas que surgem com o tratado de Luciano ou que com ele ganham uma nova formulação.

\section{III}

É ainda no âmbito das questões retóricas que se inclui o diálogo Actius, de Giovanni Pontano, escrito entre 1495 e $1499,{ }^{21}$ uma revisão do que o humanismo havia até então elaborado sobre a problemática da história. ${ }^{22}$ A sistematização que o humanista fornece "pode ser considerada como o verdadeiro ponto de partida para um discurso orgânico sobre a história, um discurso que se prepara para assumir uma dimensão agora autônoma", mesmo que em seu diálogo a história, embora possua "conteúdos e objetos próprios", não goze de "regras formais exclusivas". 23

Se Guarino da Verona postulava uma rígida separação entre história e poesia, seguindo as indicações de Luciano, por outro lado, Pontano, ao retomar a ideia de Quintiliano de que a história é uma espécie de poesia em prosa (poetica soluta), promove novamente a junção das duas, ${ }^{24}$ ou melhor, estabelece normas para a escrita historiográfica tendo como referência as questões relacionadas à ars poetica, principalmente na primeira (e maior) parte do diálogo, que trata de numeris poeticis, e à ars rhetorica, pela minuciosa preceptística apresentada na segunda parte, que abrange problemas referentes ao estilo, à linguagem, à organização do discurso, à narração dos acontecimentos

\footnotetext{
${ }^{21}$ Cf. Monti Sabia, op. cit., p. 2.

${ }^{22}$ O próprio autor declara que tal projeto havia sido intencional, uma vez que, tendo as investigações sobre a história alcançado um bom nível de maturidade em seu tempo, cabia agora estabelecer uma teoria para a disciplina histórica.

${ }^{23}$ Cf. Cotroneo, op. cit., p. 88-89.

24 "A poesia e a história têm, de fato, muitos aspectos em comum: ambas fixam a memória de fatos remotos no espaço e no tempo, descrevem lugares, povos, nações e gentes, ilustram localidades, costumes de vida, leis e hábitos, condenam os vícios e louvam as virtudes e as boas ações. Ambas, poesia e história, pertencem ao gênero literário ilustrativo, e, também, ao deliberativo, a partir do momento que oferecem exemplos de discursos, de conselhos e de deliberações" (cf. Pontano, apud Vegas, op. cit., p. 78).
} 
bélicos (já que, para Pontano, o relato historiográfico é eminentemente a narração de uma guerra), entre outros.

Portanto, mesmo quando afirma ser necessário determinar uma teoria para a história, Pontano tem em mente fixar regras, dentro de uma rica tradição gramático-retórica, para o relato historiográfico, compreendido como um artefato literário. Podemos dizer que o interesse de Pontano é voltado à historiografia, e não à "história como problema filosófico autêntico e autônomo". ${ }^{25}$

É por este viés que podemos observar a presença dos postulados de Luciano no tratado do humanista napolitano. Pontano faz uso, contudo, de um procedimento bastante peculiar, que consiste em desenvolver noções ou preceitos expostos sinteticamente pelos autores a que recorre, "fornecendo uma reelaboração amplamente articulada e filtrada através do próprio gosto e da própria sensibilidade artística" ${ }^{26}$

Para termos um exemplo, identificamos indícios de uma leitura de Luciano quando o tema da adulação é discutido: "Na história, cuja primeira lei é não escrever nada para obter favores para si mesmo e não dissimular a verdade por ódio, deve-se elogiar, no tempo e no lugar oportunos, tudo o que é digno e reprovar o que foi realizado com má intenção ou ignorância". ${ }^{27}$

Importância também é dada à brevitas, "a qualidade mais relevante na [escrita da] história", uma vez que seja "clara, aberta e compreenda de modo conveniente tudo aquilo que se deve dizer; não seja, portanto, concisão, mas meticulosa e límpida brevidade". ${ }^{28}$

Os conselhos de Luciano, referentes ao relato de uma guerra e à inserção de discursos diretos, podem ser percebidos em algumas passagens da longa preceptística voltada à descrição de guerras e batalhas, tema que ocupa uma posição central no pensamento de Pontano. Contudo, é preciso lembrar que muito do que é dito a este respeito se deve também à sua leitura de historiadores antigos, principalmente Salústio e Lívio, seus favoritos.

\footnotetext{
${ }^{25}$ Cf. Cotroneo, op. cit., p. 94.

${ }^{26}$ Cf. Monti Sabia, op. cit., p. 2-3.

${ }^{27}$ Cf. Pontano (apud Vegas, op. cit., p. 80; itálicos nossos). Comparar com Luciano, 39 e 9, respectivamente.

${ }^{28}$ Cf. Pontano (apud Vegas, op. cit., p. 80-81). Comparar com Luciano, 56.
} 


\section{IV}

Com Pontano, conclui-se o primeiro momento da reflexão humanista sobre a história, mas não se interrompe, com o seu tratado, a discussão em torno do vínculo entre história e poesia, história e retórica. O que acontece, então, é que as contribuições dos gregos passam a ocupar um lugar de destaque nos tratados posteriores. Com a primeira versão (renascentista) da Poética em latim, por Lorenzo Valla, em 1498, e a editio princeps por Aldo Manuzio, em 1508, Aristóteles passa a ser frequentemente citado, pela célebre passagem do capítulo IX, na qual afirma que a poesia, imitando o universal, está contida no âmbito da filosofia, enquanto a história, tratando do particular, filia-se à retórica. ${ }^{29}$ A visão "utilitarista" da história, num sentido mais voltado para a ação política, da qual Luciano, retomando Tucídides, é divulgador, ofusca a ideia da história como ensinamento moral ou, como em Pontano, ilustração, adorno da verdade. Neste sentido, sai de cena Quintiliano, com sua imagem da história como carmen solutum, ${ }^{30}$ embora Cícero seja constantemente recordado.

Alguns autores chegam a falar de um filão latino, que insiste "num vínculo inseparável entre história e oratória" e que "assinala à escrita da história um elevado propósito pedagógico e celebrativo", ao qual se sucede um filão grego, que busca promover a "separação entre poesia lugar do verossímil e da fabula - e história - lugar da verdade nua, alheia a celebrações empoladas. O excesso de ornatus e a acentuada idealização dos personagens representados [...] são denunciados e afastados com o recurso a um estilo rigorosamente brevis". ${ }^{31}$ Diferente também é a noção de utilitas, sobre a qual já fizemos menção.

\section{V}

É justamente este "novo" modo de perceber a utilidade da obra historiográfica um dos pontos principais do tratado de Francesco Robortello, De historica facultate disputatio, de 1548, em que ainda persistem as observações sobre a relação entre história e poesia, embora agora plasmadas numa perspectiva aristotélica, já que Robortello é um importante volgarizzatore de Aristóteles.

\footnotetext{
${ }^{29}$ Cf. Aristóteles, Poética, IX.

${ }^{30}$ Quintiliano, Institutio oratoria X, 1,31.

${ }^{31}$ Cf. Regoliosi, op. cit., p. 6-7. Ver também Cotroneo, op. cit., p. 121-122.
} 
Já no início do tratado, o autor afirma que o fim da historiografia (historica facultate) é narrar e, mais à frente, cita Luciano, para quem o "fim da história consiste em ser útil". ${ }^{32}$ Sua intenção é, portanto, enfatizar primeiramente a importância do próprio ato de narrar, que, por si, é um dos fins da historiografia, já que cabe ao historiador "narrar os fatos que realmente aconteceram". Em seguida, como a narração dos fatos segue um propósito, Robortello acrescenta: "O fim da historiografia é também ser útil". "Assim, seu tratado desenvolve, com rigor metódico, essas duas premissas. Acreditamos que esse seja um passo muito significativo para a problemática da ars historica, visto que o humanista busca conciliar duas tendências que irão se contrapor no futuro (e que em seu tempo ameaçam entrar em crise), dando uma resposta que, a nosso ver, é, senão original, estimulante, na medida em que não concebe o apagamento de uma tendência pela outra, sugerindo que o exercício narrativo, assim como as questões que o envolvem, encerra também uma função ética e política. Da mesma forma, ainda que defenda uma verdade histórica, nos mesmos moldes de Luciano, Robortello parece estar consciente de que, em algum momento, a exposição desta verdade deverá se ver às voltas com questões de argumentação. É provável que tal ideia lhe tenha sido sugerida pelo tratado de Luciano, que é constantemente retomado ao longo do texto. $\mathrm{Na}$ verdade, o tratado do professor humanista deve ser visto como um comentário, ou uma longa exposição, de Como se deve escrever a história, tendo como pano de fundo a distinção entre história e poesia proposta por Aristóteles, que, em seu aspecto geral, não se choca com as ideias do sírio.

Robortello nos fornece o melhor exemplo de como os postulados de Luciano são retomados pela ars historica no Cinquecento. Uma década depois (1559), Dionigi Atanagi publicará em Veneza seu Ragionamento della Istoria, seguindo muito de perto as indicações de Robortello, ao ponto de citar literalmente trechos inteiros de seu tratado. Estamos a um ano da publicação dos Dialoghi della historia de Francesco Patrizi da Cherso, a primeira crítica incisiva à concepção historiográfica humanista e às suas fontes, Luciano inclusive. Primeira crítica feita com rigor analítico, entenda-se, posto que menos de vinte anos antes, ali mesmo no Vêneto, Sperone Speroni havia publicado o seu Dialogo della Istoria (1542), em que Luciano é descartado logo nas primeiras páginas, e dele realmente não encontramos mais indícios por todo o texto. A crítica de

\footnotetext{
${ }^{32}$ Cf. Robortello, op. cit., p. 8.

${ }^{33}$ Cf. Robortello, op. cit., p. 10.
} 
Speroni baseia-se numa imagem que Patrizi também aceitaria: "De Luciano não direi outra coisa senão que, tendo-se exercitado por toda a vida em escrever sempre suas fábulas vãs, seus vãos diálogos e suas vãs histórias, melhor teria sido não se intrincasse de coisas sérias e verazes". ${ }^{34}$ Esta crítica nos serve como uma espécie de testemunho da reputação de que gozava então o escrito de Luciano, pois, caso contrário, não seria necessário citá-lo. Contudo, o filósofo é citado juntamente com Políbio e Dionísio de Halicarnasso, ambos também rechaçados das longas discussões dos protagonistas do diálogo.

\section{VI}

Patrizi propõe uma ruptura com a "concepção retórica" da história já no prefácio Aos leitores de seus diálogos:

Nós vos damos, cândidos leitores, dez diálogos do senhor Francesco Patrizi, nos quais são discutidas e resolvidas todas as coisas pertinentes à história (...), a qual foi, até agora, por pouquíssimos escritores, e de forma incompleta, tratada. (...) Tereis nestes Diálogos não pequena prova daquilo que do mesmo Patrizi (...) se possa esperar, em sua tão elevada empresa de toda a eloquência, que fará (...) não mais por via da observância dos três únicos gêneros, mas por via da ciência, das causas e dos princípios primeiros do falar.

A distinção que buscará estabelecer entre os Dialoghi della historia e os tratados de ars historica precedentes baseia-se numa concepção de linguagem que será plenamente elaborada em sua obra posterior, os Dialoghi della retorica, e que, de forma sucinta, podemos dizer que se pauta numa proposta de se recuperar, dentro da linha do neoplatonismo ficiniano e da imagem da prisca sapientia (retomada com a leitura de Hermes Trismegisto), o vínculo perdido entre a linguagem humana e a linguagem divina, na união entre res e verbum como perfeição conotativa.

No entanto, já nos Dialoghi della historia se enuncia a intenção de fornecer uma base científica, metodológica para uma teoria da história, "até agora" tratada de forma incompleta, visto que, para o filósofo, dentre as definições de história até então formuladas, algumas eram pouco mais do que frases de efeito e outras eram muito parciais. $\mathrm{Na}$ verdade, sua visão crítica é muito aguda: ninguém havia dito ainda o que era a história, seja porque os autores se contentavam com noções superficiais, seja porque forneciam "um empírico e desordenado acúmulo de "preceitos". 35

\footnotetext{
${ }^{34}$ Cf. Speroni, op. cit., p. 215.

${ }^{35}$ Cf. Bolzoni, op. cit., p. 66.
} 
Em suma, nenhum autor havia posto em termos filosóficos a pergunta: o que é a história? Patrizi percebe então a necessidade de uma nova definição da história, acreditando ser possível, somente a partir deste ponto, determinar seu objeto, sua finalidade, a forma de seu registro e sua utilidade.

Deste modo, os dois primeiros diálogos têm como objetivo a "demolição" daquilo que a tratadística precedente havia construído sobre a base das formulações feitas pelos antigos. E, de fato, Patrizi procede pelas bases: ao invés de passar em resenha as discussões humanistas sobre a história, o filósofo opta por uma crítica às fontes clássicas, implicitamente refutando toda a tradição que se lhes segue. Única exceção é o tratado de Pontano, talvez pelo seu aspecto de síntese do pensamento humanístico sobre o tema. Os outros autores-alvo são Cícero e Luciano.

O primeiro diálogo, O Gigante, ou Da História, se passa em Veneza e, ironicamente, começa com um elogio da história, feito por Alfonso Bidernuccio, que terá um papel semelhante ao de Fedro, no diálogo homônimo de Platão. O elogio, uma espécie de súmula dos loci communes da historiografia humanista, traz a imagem da história como

coisa sobremodo bela e útil (...) com que todo homem civil, todo senador e todo príncipe deveria, com grande estudo, deleitar-se e se familiarizar, pois que é repleta de toda forma de vida, boa ou má (...) e nela, como num espelho ou, mais verdadeiramente, num teatro, pode-se ver todas as coisas humanas, e todos os seus felizes e desventurados acontecimentos (p. 1r).

A tão "belo elogio" (p. 1v) da História, Patrizi contrapõe sua ironia socrática, primeiramente, afirmando não saber, "ainda, nem jamais [ter podido] saber, que coisa seja a história" e, logo em seguida, recorrendo aos amigos, por meio dos quais pudesse "ser, tanto sobre a história como sobre muitas outras coisas belas, doutrinado" (p. 1v). A partir deste ponto, num hábil manejo inspirado na forma dos primeiros diálogos platônicos, através do uso do elenchus, Patrizi demora-se na crítica e no "desmantelamento" das concepções tradicionais de história, conforme já dissemos.

Cícero é rapidamente refutado, tendo Bidernuccio apresentado as definições da história como "coisa feita, remota da memória dos nossos tempos" e "narração de coisas feitas, da forma como são feitas". Quanto à primeira, Patrizi demonstra ser possível que se escreva sobre acontecimentos recentes; a segunda o estudioso dispensa com ironia, afirmando, por exemplo, que explicar como é feito um par de calças estaria, assim, contido no âmbito da historiografia. 
Em relação a Luciano, o tratamento é pontual. Bidernuccio apresenta, um a um, alguns pontos de seu tratado, principalmente aqueles relacionados à preceptística do relato historiográfico. Patrizi, como se sabe, os refutará. Porém, antes do exame crítico, é a imagem caricata de um Luciano bufão, que já havíamos observado em Speroni, que Patrizi introduz e compartilha com seus interlocutores:

Bidernuccio: Apraz a Luciano que se considerem principalmente oito coisas ao se escrever a história: o princípio, a ordem, o fim, as coisas sobre as quais se deve calar, as que se deve dizer, as coisas a serem ditas de passagem, aquelas sobre as quais deve-se demorar, e como se devem narrar os fatos. Mas antes que vos refira o modo como ele mesmo no-las refere, quero, oh Patrizi, que me digais, se vos parece que ele tenha se encaminhado bem?

Patrizi: E vos direi, oh senhor Alfonso, que tenho, tanto por natureza como por costume, tanta reverência aos homens de nome elevado, que me confundo no seu lume, de modo que sou forçado, as mais vezes, a ceder àquilo que o meu espírito, de modo algum, nem quer, nem sente.

Bidernuccio: E que quereis dizer com isso?

Patrizi: O que me vem agora: que sou, pela fama deste homem, forçado a dizer que me parece que se encaminhe bem sobre [o que seja] a história, embora meu espírito me reprove por assim dizer, e me diga o contrário, o que também vos digo de má vontade, para que não me tenhais por excessivamente afetado. Sim, porque julgo que tal homem seja um dos mais finos zombeteiros que haja no mundo, pelo que temo que, se souber que não me aquieto no que diz, não se prive de lançar-me como uma bola pelas bocas de todos, com zombarias, de modo que terei depois do que me arrepender gravemente.

Gigante: Oh, essa sim é coisa de se rir. Não está morto já [há] muitas centenas de anos?

Patrizi: Não me posso fiar disto, pois também tenho medo da sua fama.

Bidernuccio: Quanto à fama, quero assegurar-vos [de que não há porque temê-la], porque não é de erudito, mas de burlão.

Patrizi: Não é, então, um homem erudito Luciano?

Bidernuccio: Não é, por certo. Mas foi grande zombeteiro como dizeis, e cortesão daqueles gentios.

Patrizi: Agora bem vedes que, não sabendo distinguir tampouco a reputação dos homens, não sei se sou um homem que valha alguma coisa. $^{36}$

\footnotetext{
${ }^{36}$ Cf. Patrizi, op. cit., 3r.
} 
Somente após conseguir a aprovação de seus interlocutores quanto ao caráter burlesco de Luciano é que Patrizi parte para a refutação de suas ideias:

Bidernuccio: Deixemos isso de parte. Mas dizei-me o que vos dita o espírito sobre o que vos contei.

Patrizi: Vo-lo direi precisamente o que me dita. Ele assim argumenta: Oh, minha sombra, ${ }^{37}$ se quisesses saber que coisa fosse o homem, não buscarias a definição? Naturalmente, digo eu. A qual, ele acrescenta, lhe fosse tão própria, que a outras coisas não pudesse se aplicar? Exatamente assim. Como esta: o homem é animal de uma cabeça, de dois braços e de dois pés, com espáduas, peito, ventre e coxas. Talvez seja essa, respondo. E se quisesses definir um símio, replica ele, uma mona, ou um sátiro, não dirias serem eles animais de uma cabeça, de dois braços, de dois pés, com espáduas, peito, ventre e coxas? Naturalmente. Portanto, diz ele, de que modo é esta definição tão própria do homem, se também é própria destes outros? De modo algum, respondo todo admirado. Mas esta outra, diz ele, lhe será bem própria: que o homem seja um animal racional e mortal, porque nenhum dos outros é racional, e nenhum anjo ou demônio é mortal. É verdade, digo eu. E é também verdadeira e própria esta definição do homem. É também verdadeira e própria, digo, mas que queres dizer com isso, espírito meu? Que, me responde ele, para saber o que é uma coisa, não convém parti-la em todas aquelas partes que também sejam comuns a muitas outras coisas. Dizes a verdade, digo eu, e por que razão? Porque não se pode saber o que seja a história, diz ele, com o dito de que é preciso considerar que ela tenha tal começo, tal meio e tal fim. E por quê, digo eu? Não vês, replica ele, que essas coisas não pertencem apenas ao historiador, mas a todos os outros escritores igualmente, e mais, a todas as coisas do mundo também? Dizes a verdade, lhe respondo. E, por isso, seria certo dizer,

${ }^{37}$ Indício da filiação de Patrizi ao neoplatonismo ficiniano, o termo é usado no sentido de que o aspecto fenomenológico, efêmero, do mundo (e, portanto, o corpo físico, a existência material) nada mais é do que sombras, se comparado ao real. É uma noção que pode ser facilmente percebida na célebre alegoria da caverna, na República (514A-517D). Na passagem em questão, Patrizi introduz uma imagem que será retomada ao longo dos diálogos: a de que se deixa guiar por aquilo que lhe determina o espírito. Tal imagem se torna mais clara se confrontada com as passagens relacionadas ao mito da alma como um carro alado, no Fedro (246A-256E). Se o homem conseguir deixar-se conduzir pelas partes mais elevadas de sua alma, submetendo as paixões ao domínio racional das virtudes intelectivas, lhe será possível viver uma existência equilibrada e feliz, consagrada à filosofia. 
acrescenta o espírito, ao poeta, ao filósofo, ao orador e a qualquer outro escritor: começa desta forma, prossegue nesta outra e, finalmente, termina naquela outra. Isso é muitíssimo verdadeiro. E, da mesma forma, replica ele, pode-se dizer ao orador: oh, orador, procura não dizer isto e isto diz; e isto, dize-o de passagem; e sobre aquilo demora; e isto, diz de tal maneira. Dizes a verdade, espírito meu, lhe respondo. Portanto, oh, minha sombra, me diz ele, não são próprias do historiador as coisas ditas por Luciano. ${ }^{38}$

Na sequência do diálogo, Bidernuccio recorda dois temas centrais em Luciano: o compromisso com a verdade do que se escreve e a objeção ao uso dos elogios e da adulação. Depois disso, um ou outro tema é debatido e, por fim, Patrizi encerra a discussão:

Patrizi: Podemos, portanto, nós, que buscamos o que seja a história, dizer, segundo ele, que seja algo em que é preciso observar o princípio, a ordem, o fim, as coisas as quais dizer, aquelas sobre as quais silenciar, umas a se evitar, e outras a se estender. Algo em que não se deve dizer mentiras. E, sucessivamente, juntando tudo o que ele considerou, teremos uma longuíssima definição da história. ${ }^{39}$

O filósofo habilmente revisa e simplifica os pontos discutidos e finge aceitar a definição que deles se pode extrair, deixando para um surpreso Bidernuccio a conclusão: "De fato, ele não a definiu, mas nos disse somente de que partes deve ser composta, e como deve ser seu escritor". ${ }^{40}$

Há, na crítica de Patrizi, uma preocupação em denunciar toda uma concepção de história que mantenha um vínculo de dependência com os preceitos da retórica tradicional, daí/donde o anseio do filósofo por uma linguagem que não seja mais dominada pelo medo e pela adulação, ${ }^{41}$ como

${ }^{38}$ Cf. Patrizi, op. cit., 3r-3v.

${ }^{39}$ Cf. Patrizi, op. cit., p. $4 \mathrm{v}$.

${ }^{40}$ Cf. Patrizi, op. cit., p. $4 \mathrm{v}$.

${ }^{41}$ Patrizi não se engana em relação à dificuldade, ou, até mesmo, impossibilidade, de se chegar a um procedimento de escrita cuja linguagem expresse o verdadeiro, $\mathrm{o}$ que o leva a indagar se há uma verdade histórica. Dois fatores estarão sempre presentes nas reflexões acerca dessa verdade: a intenção (ou uma possível condição) do historiador em expressá-la e, o que é ainda mais árduo, o acesso completo aos reais desígnios dos "atores". Todo o quinto diálogo, Il Conti leo vero della verita dell'historia, gira em torno do tema. Nestas páginas, das mais céticas e irônicas da obra, a estrutura dos diálogos aporéticos de Platão é intensamente retomada, e o método elenquístico possibilita a adoção de certos pontos de vista que, posteriormente, serão refutados 
mero instrumento de poder político (tema que, além de ser desenvolvido no quinto diálogo, será retomado dois anos mais tarde, nos Dialoghi della retorica), ainda que a utilidade da história seja eminentemente política (diálogo IX). ${ }^{42}$ A diferença é que Patrizi propõe uma união entre filosofia e história, pois, sendo a felicidade humana o fim da história, que, por sua vez, só é alcançável dentro de uma "comunidade de homens felizes" (p. 24r), somente "onde todos os cidadãos são felizes, cada um é também

numa constante, até que o diálogo se encerre com um sentimento de desolação: "Em suma, a história se tornou poesia. Oh, foi justamente este o golpe que cortou completamente toda esperança que me podia restar de ver a história verdadeira" (p. 30r). Isto porque Luca Contile, o protagonista do diálogo, a princípio, nega que o historiador diga a verdade, pois, sendo "homem do vulgo, (...) nos fará história das coisas da rua, e teremos belíssimas novelas", e sendo "homem de governo", se submeterá a dois deuses: "A adulação (...) e o medo, um dos quais sempre engrandece com mentiras as coisas relacionadas a seu príncipe, e o outro cala a verdade" (p. $27 \mathrm{v})$. Tendo, porém, a intenção de dizer a verdade, será obstado de participar do conselho dos príncipes, "capitais inimigos da verdade" (p. 28r). Restam, por fim, somente as "novelas da praça". Por isso a alusão à poesia.

${ }^{42}$ A visão desoladora da impossibilidade de uma historiografia capaz de registrar a verdade, que observamos no quinto diálogo, e da incapacidade humana de uma cognição plena do mundo, tema que abre o diálogo IX, se confronta com o discurso de Leonardo Donà, retomando os pontos principais dos diálogos anteriores e dandolhes uma elaboração final. Donà parte do pressuposto de que, assim como a tragédia pode "portar utilidade ao homem que entende" (p. 50r), a história também é capaz de fazê-lo, convertendo, porém, "lição em ação" (p. 50v). O grande quadro apresentado em diálogos anteriores, de alargamento da matéria histórica, se reduz drasticamente à utilidade pública do conhecimento histórico, rejeitando, inclusive, seu emprego, pelo homem, para benefício próprio, pois "tira melhor vantagem da história quem o faz por sua pátria, ao invés de fazê-lo para si mesmo". Donà reafirma que o fim da história é a felicidade, que "nada mais é do que uma união que fazemos com Deus por meio da contemplação" (p. 51r). Contudo, a seguir, pondera que a vida contemplativa é alcançada quando os afetos são apaziguados pelas "virtudes e bons costumes, e as outras coisas a isso necessárias" o que se dá somente se o homem "se põe a viver com outros homens em comum", na cidade, pois este é o único lugar propício para a satisfação de seus três desejos: "ser, bem ser e sempre ser” (p. 51r). O estado de paz é necessário para qualquer cidade que queira ser feliz. Obviamente, a guerra deve ser evitada, ou, caso haja necessidade de empreendê-la, que tenha como mira a paz, que advém com seu término. Porém, ainda mais perigosa é a sedição, pois sendo ela "inimiga doméstica, (...) [destrói] o ser, pela matança e pelas mortes que ela traz consigo. Destrói o bem ser, com as suspeitas e com as inimizades, com privações de coisas e de honrarias, com os contínuos afãs e com os contínuos temores, e com semelhantes e infindas misérias. Anula também o sempre 
feliz" (p. 51v). Para atingir este fim, três modos são possíveis: "as contemplações universais", incumbência do filósofo; "a cognição dos casos particulares", ocupação do historiador; ou "uma e outra juntamente" (p. 24r). De fato, como observa Leinkauf, ${ }^{43}$ para Patrizi, "a história deve ser, ao lado da filosofia como ciência das causas e das razões, a ciência dos efeitos ou realidades que têm seu fundamento em causas". É neste sentido mais amplo que devemos interpretar a "cognição dos casos particulares". Não mais a ação em si, mas as causas que levam a cabo tal ação que importam.

Há um outro aspecto que não deve ser negligenciado. Segundo Vasoli,

A atitude mental de que é expressão o livro de Patrizi nascia, porém, também, se não sobretudo, do clima político e "institucional" do tempo, da definitiva queda dos antigos regimes "republicanos" (que, na verdade, haviam sido, quase sempre, poderes patrícios e oligárquicos), por todos os lugares suplantados pelo domínio habsbúrgico ou por "príncipes novos"; e ainda, pela perigosa situação da Contra-Reforma, já próxima de cristalizar-se nos decretos tridentinos. $^{44}$

É, portanto, um modelo cultural em crise este que Patrizi rejeita, embora possamos encontrar as máximas e preceitos de Cícero e Luciano sendo incansavelmente repetidos por todo o Cinquecento, adentrando o século XVII. Porém, neste caso, tais formulações carecem do vigor argumentativo de pensadores como Guarino ou Pontano, e assim, pari passu à grande profusão de artes historicae, não se observa, como se poderia esperar, um debate intelectual intenso e fértil acerca do tema.

ser, matando, com a privação dos filhos e com o banimento dos bons estudos e de outras obras egrégias, a tão desejada eternidade" (p. 52v). As dissensões civis não têm fundamento numa cidade onde haja "tranquilidade no coração dos cidadãos", e onde estes, "que são pelas leis introduzidos às honras da cidade, para contentamento da parte animosa de nosso espírito, delas são feitos partícipes". Portanto, um cuidado especial deve ser colocado "na sua formação, nas leis e nos cargos de cada ordem da cidadania” (p. 51v), meios pelos quais a paz estará garantida. Por fim, concorrem, para a excelência destas instituições, "duas vias, otimamente: (...) a dos filósofos, e (...) a dos historiadores, uns dos quais nos ensinam por meio das causas, estando voltados ao universal, e os outros, por meio do particular e da experiência” (p. 51r).

${ }^{43}$ Cf. Leinkauf, op. cit., p. 230-231.

${ }^{44}$ Cf. Vasoli, op. cit., p. 92. 


\section{Referências}

ARISTÓTELES. Poética. Trad. Eudoro de Souza. São Paulo: Ars Poetica, 1993.

BOLZONI, L. L'universo dei poemi possibili: studi su Francesco Patrizi da Cherso. Roma: Bulzoni, 1980.

BRANDÃO, J. L. A "pura liberdade" do poeta e o historiador. Ágora: Estudos Clássicos em Debate, Aveiro, vol. 9, p. 9-40, 2007.

COTRONEO, G. I trattatisti dell' 'Ars historica”. Napoli: Francesco Giannini \& Figli, 1971.

GARIN, E. Il pensiero pedagogico dello Umanesimo. Firenze: Giuntine, 1958.

GARIN, E. L'umanesimo italiano. Roma: Laterza, 1993.

GRAFTON, A. What was History? The art of History in early modern Europe. Cambridge: Cambridge University Press, 2007.

GUARINO DA VERONA. Epistola a Tobia del Borgo. In: VEGAS, F. La concezione della storia dall'Umanesimo alla Controriforma. In: SCIACCA, M. F. (dir.); MOSCHETTI, A. M.; SCHIAVONE, M. (coord.). Grande antologia filosofica:X, Il pensiero della Rinascenza e della Riforma (Protestantesimo e Riforma Cattolica). Milano: Marzorati Editore, 1964, p.71-77.

HARTOG, F. A história de Homero a Santo Agostinho. Trad. Jacyntho Lins Brandão. Belo Horizonte: UFMG, 2001.

KELLEY, D.R. The Theory of History. In: SCHIMITT, Charles B. \& SKINNER, Quentin (ed.). The Cambridge History of Renaissance Philosophy. Cambridge: Cambridge University Press, 2000.

LEINKAUF, T. Francesco Patrizi: novas filosofias da história, da poesia e do mundo. In: BLUM, P. R. (org.). Filósofos da Renascença. São Leopoldo: Editora Unisinos, 2003, p. 228-246.

LUCIANO DE SAMÓSATA. Como se deve escrever a História. Trad. Jacyntho Lins Brandão. Belo Horizonte: Tessitura, 2009.

MONTI SABIA, L. Pontano e la storia: dal "De bello Neapolitano"all' “Actius”. Roma: Bulzoni, 1995.

PATRIZI, F. Della historia diece dialoghi di M. Francesco Patritio ne' quali siragiona di tutte le cose appartenenti all'historia, E allo scriverla, E all'osservarla.Venetia: Andrea Arrivabene, MDLX.

PLATONE. Fedro. In: REALE, G. (org.). Platone: tutti gli scritti. Milano: R.C.S. Libri, 2005, p. 536-595.

PLATONE. Repubblica. In: REALE, G. (org.). Platone: tuttigli scritti. Milano: R.C.S. Libri, 2005, p. 1068-1347.

PONTANO, G. "Actius”. In: PONTANO, G. I Dialoghi. A cura di Carmelo Previtera. Firenze: Sansoni, 1943, p. 123-239. 
PONTANO, G. “Actius”. In: VEGAS, F. La concezione della storia dall' Umanesimo alla Contro riforma. In: SCIACCA, M. F. (dir.); MOSCHETTI, A. M.; SCHIAVONE, M. (coord.). Grande antologia filosofica: X, Il pensiero della Rinascenza e della Riforma (Protestantesimo e Riforma Cattolica). Milano: Marzorati Editore, 1964, p. $78-84$.

QUINTILIAN. The orator's education. Trad. Donald A. Russell. Vol. I-IV. Cambridge, Mass./ London: Harvard University Press, 2001.

REGOLIOSI, M. Riflessioni umanistiche sullo "scrivere storia”. Rinascimento Rivista dell'Istituto Nazionale di Studi sul Rinascimento, Firenze, seconda serie, vol. XXXI, p.3-37, 1991.

REYNOLDS, B. Shifting currents in Historical Criticism.In: KRISTELLER, P. O.; WIENER, P. P. (org.). Renaissance essays. New York: University of Rochester Press, 1992, p. 115-136.

ROBORTELLO, F. De historia facultate. In: KESSLER, E. Theoretiker humanistischer Geschichtsschreibung. München: Wilhelm Fink Verlag, 1971.

SPERONE SPERONI. Dialogo della Istoria. In: SPERONE SPERONI. Opere. Org. Mario Pozzi. Roma: Vecchiarelli Editore, 1989, p. 210-238.

ULLMAN, B. L. Leonardo Bruni and Humanistic Historiography. In: ULLMAN, B.L. Studies in the Italian Renaissance. Roma: Edizioni di Storia e Letteratura, 1973, p. 321-344.

VASOLI, C. Francesco Patrizi da Cherso. Roma: Bulzoni, 1989.

VEGAS, F. La concezione della storia dall'Umanesimo alla Controriforma. In: SCIACCA, M. F. (dir.); MOSCHETTI, A. M.; SCHIAVONE, M. (coord.). Grande antologia filosofica: X, Il pensiero della Rinascenza e della Riforma (Protestantesimo e Riforma Cattolica). Milano: Marzorati Editore, 1964, p. 1-59. 